\title{
Morphological differences of hindlimb levers between wild and farmed American mink (Neovison vison) and implications for reintroduction of mustelids
}

\author{
Jian Sun ${ }^{1} \cdot$ Xiaoli Zhou ${ }^{1} \cdot$ Yanchun Xu$^{1,2,3} \cdot$ Yan Hua $^{1}$. \\ Thomas D. Dahmer ${ }^{4} \cdot$ Shuhui Yang ${ }^{1}$
}

Received: 26 February 2019 / Accepted: 6 May 2019 / Published online: 28 November 2019

(C) The Author(s) 2019

\begin{abstract}
Reintroduction is an important strategy to restore or re-establish wild populations of endangered species. Pre-release training is a necessary step to ensure postreintroduction survival. However, studies reported contradicting outcomes after pre-release training of juveniles and adults. This study used farmed and feral American mink (Neovison vison) to analyze the influence of captive breeding on the morphology, structure and efficiency of the two major hindlimb levers, the femur and tibia pivoted by hip and knee joints that are essential for locomotion. Results showed that captive breeding did not alter the sexual dimorphism of the two levers that are related to survival in the wild. Captive-bred mink showed slightly altered morphology of the femur and fundamental structure of the hindlimb levers that improved efficiency, but this resulted in reduction
\end{abstract}

Project funding: The project was fully funded by China State Forestry and Grassland Administration Project for Rescue and Captive Breeding of Endangered and Rare Wildlife (2018).

The online version is available at http://www.springerlink.com.

Corresponding editor: Yu Lei.

Shuhui Yang

474568251@qq.com

1 College of Wildlife and Protected Area, Northeast Forestry University, No. 26, Hexing Road, Harbin 150040, People's Republic of China

2 State Forestry and Grassland Administration Research Center of Engineering Technology for Wildlife Conservation and Utilization of China, No. 26, Hexing Road, Harbin 150040, People's Republic of China

3 State Forestry and Grassland Administration Detecting Center of Wildlife, No. 26, Hexing Road, Harbin 150040, People's Republic of China

4 Ecosystems Ltd, Hong Kong, People's Republic of China of performance related to foraging in both terrestrial and aquatic environments, especially for females. These findings suggest that reintroduction of mustelid as exampled by the mink here should focus on juveniles because the skeletal alterations associated with captive rearing were recorded only among adults and are irreversible in adulthood. In contrast, captive-reared juveniles showed no skeletal alterations and would be expected to recovery from any atrophy of the muscular system caused by captive rearing for shorter durations. Our results support the application of pre-release training of juveniles in enriched environments as a method for alleviating structural alteration of appendages and enhancing locomotion to increase survival probability in complex habitats.

Keywords Hindlimb lever · Morphology · American mink $\cdot$ Neovison vison $\cdot$ Reintroduction

\section{Introduction}

Mustelid species are threatened worldwide with a higher proportion of species and subspecies threatened (38\%) than of other mammal species (15\%) as results of alterations in water quality, habitat modification, intensive trapping, and competition in communities (Bright 2000; Lodé et al. 2001). Reintroduction is an important strategy to re-establish wild populations (Kleiman 1989). Trials of this strategy have been made for mustelid species, such as black-footed ferret, wolverine, European otter, and fisher. The percent of captive bred animals surviving reintroduction was about half of those caught from the wild (Jule et al. 2008). The reasons for the success or failure often remain unclear and the outcomes are hard to predict. 
Factors being identified to affect post-release survival include experience in detection and avoidance of predators (Griffin et al. 2000; Shier and Owings 2006; Bremner-Harrison et al. 2004), searching for and catching prey (Biggins et al. 1999), the physiological capacity to endure thirst and starvation, and disease resistance (Jule et al. 2008). However, specific experiences generalized from mustelid reintroduction trials mostly relate to environment or habitat issues and release methods (soft release, i.e., animals are kept in outdoor cages for several days at a reintroduction site prior to release versus hard release, i.e., animals are released directly into a novel site) and number of animals released at a given location (Bright 2000). Studies addressing animal physiological ability have been few.

Animals bred in captivity for reintroduction programs normally lack the survival capabilities listed above. A common management practice to counter inexperience is prerelease training of captive-bred animals. Pre-release training programs typically aim to improve experiences and behaviors for living in the wild by means such as environmental enrichment (Shepherdson 1994; Box 1991; Vargas and Anderson 1999; Maran et al. 2009) and exposure of animals to predators or predators' odors (Griffin et al. 2001; Blumstein et al. 2002). Training of juveniles often results in better post-reintroduction survival than training of adults (Priddel and Wheeler 1996; Stoinski and Beck 2004; Shier and Owings 2007; Robert et al. 2004). This might be because the juvenile life stage is naturally a period for behavioral and physiological training whereas adults have already adapted to the captive environment and have less plasticity in behavior and physiology. However, some studies were unable to demonstrate a difference between juveniles and adults (Maran et al. 2009), and other studies reported poorer results in juveniles (Sarrazin and Legendre 2000). These conflicting results complicate the choice of a candidate age-class for pre-release training. The choice between juveniles and adults is complicated by the interplay between physiological and environmental parameters. It could be made more objectively if physiological parameters are fully considered.

Locomotion parameters such as acceleration, maximum velocity, agility, and endurance will determine successful adaptation to a wild environment (Carrier 1996). Locomotion is the outcome of interactions between the neural and musculoskeletal systems but is ultimately determined by interactions between the muscular and skeletal systems and, in particular, in the lever systems around joints (Higham 2007).

The muscular system has high plasticity in mass and contraction force both of which are responsive to physical exercise (Flück 2006). Resistance training leads to muscle hypertrophy and increased contraction force (Marini and Veicsteinas 2010). Conspecifics living in different environments can have different behavior profiles, leading to differing intensities of use of skeletal muscles and, in turn, to differing muscle masses and contraction forces. Developing bones in young animals respond to force by changing morphology, while adult bones respond to force primarily by increasing density (Järvinen et al. 2003). Animals raised in different environments are exposed to different muscular forces and this can result in differentiation of bone structures (Burger and Klein-Nulen 1999). Captivereared animals are typically held in enclosures that constrain or prevent body movements that would normally be undertaken in the wild. When considered together, the points listed above suggest two hypotheses for testing: (1) Captive rearing is likely to result in changes in muscle and/or bone mass and structure that could lead to sub-optimal locomotor performance and hence lower probability of post-release survival; and (2) Appropriate pre-release training of juveniles might counter these adverse effects of captive-rearing.

Samples for testing are rarely available from reintroduction programs involving endangered species. To obtain sufficient sample sizes for hypothesis testing, we investigated American mink (Neovison vison), which has been extensively farmed for fur since 1925 (Larivière 1999). At the northern extent of the Greater Xing' an Mountains of northeast China, mink farms were first set up in the 1960s. Mink occasionally escaped the farms and this led to establishment of a free-ranging population that has been exploited by local fur trappers almost since the time of the establishment of the farms.

In the wild, mink are subjected to natural selection for performance traits appropriate to survival in the wild. In mink farms in more developed economies, selection focuses on production and welfare-related traits such as fur quality, reproductive performance and tame behaviors (Rönningen et al. 1980; Hansen 1996; Hansen et al. 2010). However, farms in the Greater Xing' an Mountains do not selectively breed mink for any particular performance traits. Rather, they introduce breeding animals every several years (one generation per year) from advanced farms (Guo et al. 2006). This situation parallels most captive breeding of endangered species in zoos, safari parks, and reintroduction bases where animals are not culled based on poor performance. Because of its history of captive-rearing followed by escape to the wild, the American mink in northeast China is an ideal subject to test the effects of captive rearing on traits related to post-reintroduction survival and, in this instance, the effects on muscular and skeletal morphology.

We collected farmed and feral American mink in the northern Greater Xing'an Mountains of northeast China. We compared the morphological differences between farm and wild groups in the two major hindlimb lever systems that are essential for jumping, running and posture adjustment, viz. the femur lever system and the tibia lever system 
(Fig. 1). Our findings provide a new sight of physiology to predict success probability for reintroduction of mustelids.

\section{Materials and methods}

Thirty-two adult feral American mink (9 males, 23 females) were trapped from November 2011 to January 2012 in the northern Greater Xing' an Mountains of Heilongjiang Province, China, and 45 carcasses of adult farmed mink (35 males and 10 females) were obtained from a farm in the same region. The carcasses were preserved outdoors (temperature varied from -22 to $-42{ }^{\circ} \mathrm{C}$ ) for about two and half months after being pelted. Muscle tissues of carcasses dried to varying degrees.

Adductor and gastrocnemius were isolated from the hindlimbs and dried at $75^{\circ} \mathrm{C}$ for over $48 \mathrm{~h}$ until the weight was constant. Each muscle was weighed using an AL204 analytical balance (Mettler-Toledo, USA) with $0.01 \mathrm{~g}$ sensitivity. Femur and tibia were isolated and remaining muscles and tendons were completely removed and dried in an oven. The lengths of femur and tibia were measured to $\pm 0.1 \mathrm{~mm}$ using a ruler. The shapes of the condyle and

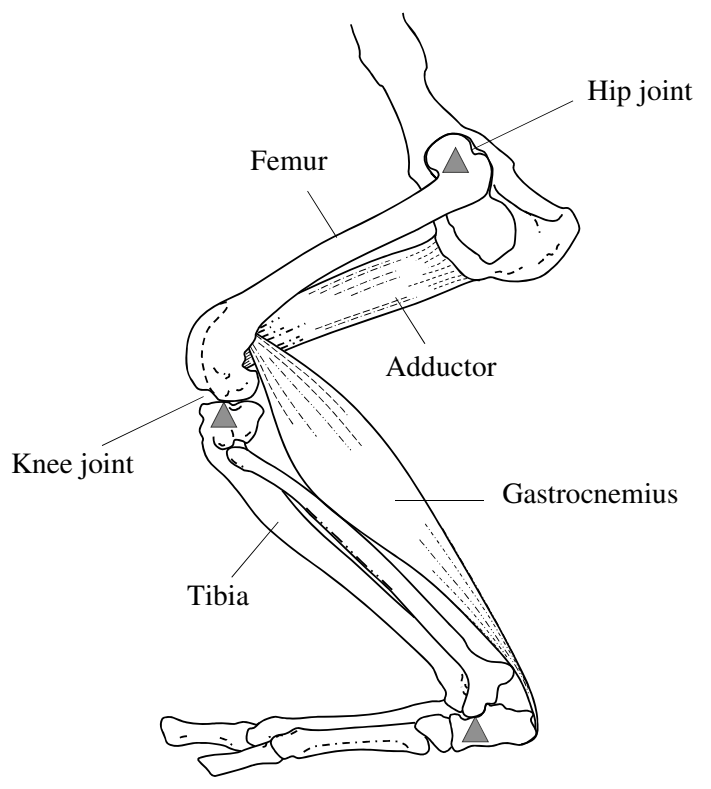

Fig. 1 Diagram of hindlimb levers of the American mink. The femur lever is comprised of femur (the moment arm) and hip joint (the pivot). Adductor is one of the muscles that provides effort force to move the femur rearward and inward for standing and jumping. The tibia lever is comprised of the tibia and the knee joint. Muscles providing effort force are not shown. The calcaneus lever is comprised of the calcaneus and tibiotarsal joint. The gastrocnemius provides effort force to lift the heel and places axial load to the tibia. The femur and tibia levers are third class levers in which the effort is between the resistance and the pivot (upward filled triangle), and the calcaneus lever is a first class lever in which the pivot lies between the effort and resistance muscular enthesis were examined, and the height of condyle ( $\mathrm{W}_{\mathrm{c}}$ and $\mathrm{H}_{\mathrm{c}}$ respectively), diameter and length of femoral head $\left(D_{h}\right.$ and $\left.L_{h}\right)$, and major and minor diameters of femoral diaphysis $\left(\mathrm{D}_{\mathrm{mj}}\right.$ and $\left.\mathrm{D}_{\mathrm{nm}}\right)$ were measured using a Vernier caliper (Fig. 2). The enthesis of gastrocnemius (GE) below the femoral condyle were visually graded as indistinct (ID), moderately distinct (MD) and extremely distinct (ED) according to size. Grading of GE was performed by three separate technicians whose grades were harmonized before being recorded.

Lever structure was described using the length of the moment arm, the femur $\left(\mathrm{L}_{\mathrm{f}}\right)$. Lever performance was defined as the ratio of adductor mass to femur length $\left(\mathrm{M}_{\mathrm{a}} / \mathrm{L}_{\mathrm{f}}\right)$. This parameter describes the effort force the muscle exerts per unit length of moment arm. The axial load that the gastrocnemius exerts on the tibia was used to infer the structural and mechanical improvements of this bone according to the findings that axial compression can positively impact on architecture and mechanical behavior in the diaphysis (Berman et al. 2015). The two levers work in tandem for completing a motion. Thus we tested the structural relatedness between the two levers using Spearman bivariate correlation analysis of $\mathrm{L}_{\mathrm{f}}$ and $\mathrm{L}_{\mathrm{t}}$. The mean values of $\mathrm{L}_{\mathrm{f}}, \mathrm{L}_{\mathrm{t}}, \mathrm{M}_{\mathrm{a}} / \mathrm{L}_{\mathrm{f}}$ and $\mathrm{M}_{\mathrm{g}} /$ $\mathrm{L}_{\mathrm{t}}$ were compared between sexes and origin groups (farm versus wild) using independent samples t-test at $\alpha=0.05$. All statistical analyses were computed using SPSS 13.0 software (SPSS Inc., Chicago, IL, USA).

\section{Results}

\section{Morphological differences of femur}

The shapes of the femoral condyle, head, and diaphysis were quantified as listed in Table 1. Significant sexual dimorphism was recorded for $\mathrm{W}_{\mathrm{c}}, \mathrm{H}_{\mathrm{c}}, \mathrm{D}_{\mathrm{h}}, \mathrm{L}_{\mathrm{h}}, \mathrm{D}_{\mathrm{mj}}$ and $\mathrm{D}_{\mathrm{nm}}$ with all means greater for males than for females in both wild
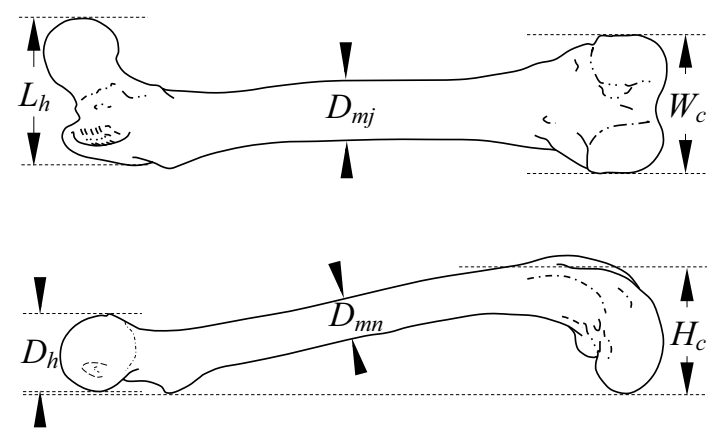

Fig. 2 Diagram of measurements on the femur of the American mink. $W_{c}$ is width of condyle; $H_{c}$ is height of condyle; $D_{h}$ is diameter of femoral head; $L_{h}$ is length of femoral head; $D_{m j}$ is major diameters of femoral diaphysis; $\mathrm{D}_{\mathrm{nm}}$ is minor diameters of femoral diaphysis 
Table 1 Parameters of hindlimb levers in wild and farmed American mink

\begin{tabular}{|c|c|c|c|c|c|c|}
\hline \multirow[t]{2}{*}{ Parameters } & \multicolumn{3}{|c|}{ Wild mink } & \multicolumn{3}{|c|}{ Farmed mink } \\
\hline & Male & Female & Pooled & Male & Female & Pooled \\
\hline \multicolumn{7}{|c|}{ Femur length $\left(\mathrm{L}_{\mathrm{f}}, \mathrm{mm}\right)$} \\
\hline Minimum & 47.0 & 43.5 & 43.5 & 54.5 & 47.5 & 47.5 \\
\hline Maximum & 57.0 & 57.0 & 57.0 & 62.0 & 54.5 & 62.0 \\
\hline Mean & 51.5 & 44.1 & 46.3 & 58.1 & 50.0 & 55.8 \\
\hline SD & 3.1 & 1.4 & 3.9 & 2.1 & 2.0 & 4.3 \\
\hline \multicolumn{7}{|c|}{ Tibia length $\left(\mathrm{L}_{\mathrm{t}}, \mathrm{mm}\right)$} \\
\hline Minimum & 46.9 & 41.4 & 41.4 & 53.0 & 46.8 & 46.8 \\
\hline Maximum & 55.9 & 46.9 & 55.9 & 61.8 & 53.4 & 61.8 \\
\hline Mean & 51.7 & 44.1 & 46.3 & 58.2 & 49.6 & 55.8 \\
\hline SD & 3.2 & 1.6 & 4.1 & 2.2 & 1.7 & 4.4 \\
\hline \multicolumn{7}{|c|}{ Condyle width $\left(\mathrm{W}_{\mathrm{c}}, \mathrm{mm}\right)$} \\
\hline Minimum & 11.5 & 10.0 & 10.0 & 13.0 & 10.5 & 10.5 \\
\hline Maximum & 13.0 & 11.5 & 13.0 & 14.5 & 12.5 & 14.5 \\
\hline Mean & 12.4 & 10.6 & 11.1 & 13.8 & 11.6 & 13.2 \\
\hline SD & 0.5 & 0.4 & 0.9 & 0.4 & 0.6 & 1.1 \\
\hline \multicolumn{7}{|c|}{ Condyle height $\left(\mathrm{H}_{\mathrm{c}}, \mathrm{mm}\right)$} \\
\hline Minimum & 9.0 & 7.9 & 7.9 & 11.0 & 9.0 & 9.0 \\
\hline Maximum & 10.9 & 9.3 & 10.9 & 22.1 & 12.1 & 22.1 \\
\hline Mean & 9.9 & 8.4 & 8.8 & 12.3 & 10.2 & 11.8 \\
\hline SD & 0.5 & 0.3 & 0.8 & 1.9 & 0.8 & 2.0 \\
\hline \multicolumn{7}{|c|}{ Femoral head diameter $\left(D_{h}, \mathrm{~mm}\right)$} \\
\hline Minimum & 7.1 & 5.5 & 5.5 & 7.8 & 6.2 & 6.2 \\
\hline Maximum & 8.5 & 6.7 & 8.5 & 11.0 & 7.8 & 11.0 \\
\hline Mean & 7.9 & 6.1 & 6.6 & 9.2 & 7.1 & 8.7 \\
\hline SD & 0.5 & 0.4 & 0.9 & 0.8 & 0.5 & 1.2 \\
\hline \multicolumn{7}{|c|}{ Femoral head length $\left(\mathrm{L}_{\mathrm{h}}, \mathrm{mm}\right)$} \\
\hline Minimum & 12.0 & 10.5 & 10.5 & 13.0 & 11.0 & 11.0 \\
\hline Maximum & 14.5 & 12.0 & 14.5 & 16.0 & 13.0 & 16.0 \\
\hline Mean & 13.1 & 11.1 & 11.7 & 14.4 & 12.0 & 13.8 \\
\hline SD & 0.7 & 0.4 & 1.0 & 0.7 & 0.5 & 1.2 \\
\hline \multicolumn{7}{|c|}{ Femoral diaphysis Major diameter $\left(D_{m j}, m m\right)$} \\
\hline Minimum & 3.8 & 3.3 & 3.3 & 4.7 & 3.9 & 3.9 \\
\hline Maximum & 4.8 & 4.2 & 4.8 & 6.0 & 4.9 & 6.0 \\
\hline Mean & 4.3 & 3.7 & 3.9 & 5.4 & 4.4 & 5.1 \\
\hline SD & 0.4 & 0.2 & 0.4 & 0.3 & 0.3 & 0.5 \\
\hline \multicolumn{7}{|c|}{ Femoral diaphysis minor diameter $\left(\mathrm{D}_{\mathrm{mn}}, \mathrm{mm}\right)$} \\
\hline Minimum & 3.5 & 3.0 & 3.0 & 3.8 & 3.3 & 3.3 \\
\hline Maximum & 4.2 & 3.6 & 4.2 & 4.8 & 4.0 & 4.8 \\
\hline Mean & 3.7 & 3.2 & 3.4 & 4.4 & 3.6 & 4.2 \\
\hline SD & 0.2 & 0.2 & 0.3 & 0.2 & 0.2 & 0.4 \\
\hline \multicolumn{7}{|c|}{ Adductor dry mass $\left(\mathrm{M}_{\mathrm{a}}, \mathrm{g}\right)$} \\
\hline Minimum & 0.85 & 0.34 & 0.34 & 1.46 & 0.63 & 0.63 \\
\hline Maximum & 1.51 & 1.04 & 1.51 & 2.53 & 1.31 & 2.53 \\
\hline Mean & 1.23 & 0.66 & 0.81 & 2.17 & 1.03 & 1.85 \\
\hline SD & 0.25 & 0.17 & 0.32 & 0.27 & 0.20 & 0.58 \\
\hline \multicolumn{7}{|c|}{ Gastrocnemius dry mass $\left(\mathrm{M}_{\mathrm{g}}, \mathrm{g}\right)$} \\
\hline Minimum & 0.98 & 0.43 & 0.43 & 1.15 & 0.63 & 0.63 \\
\hline Maximum & 1.50 & 0.93 & 1.50 & 2.62 & 1.19 & 2.62 \\
\hline Mean & 1.21 & 0.68 & 0.81 & 1.98 & 0.98 & 1.69 \\
\hline
\end{tabular}


Table 1 (continued)

\begin{tabular}{|c|c|c|c|c|c|c|}
\hline \multirow[t]{2}{*}{ Parameters } & \multicolumn{3}{|c|}{ Wild mink } & \multicolumn{3}{|c|}{ Farmed mink } \\
\hline & Male & Female & Pooled & Male & Female & Pooled \\
\hline SD & 0.20 & 0.12 & 0.27 & 0.26 & 0.18 & 0.52 \\
\hline \multicolumn{7}{|l|}{$\mathrm{L}_{\mathrm{f}} / \mathrm{L}_{\mathrm{t}}$} \\
\hline Minimum & 0.98 & 0.97 & 0.97 & 0.95 & 0.99 & 0.95 \\
\hline Maximum & 1.02 & 1.02 & 1.02 & 1.12 & 1.02 & 1.12 \\
\hline Mean & 0.99 & 1.00 & 1.00 & 1.00 & 1.01 & 1.00 \\
\hline SD & 0.02 & 0.01 & 0.01 & 0.03 & 0.01 & 0.03 \\
\hline \multicolumn{7}{|l|}{$\mathrm{M}_{\mathrm{a}} / \mathrm{L}_{\mathrm{f}}(\mathrm{g} / \mathrm{m})$} \\
\hline Minimum & 18.13 & 7.43 & 7.43 & 26.12 & 12.46 & 12.46 \\
\hline Maximum & 23.74 & 14.92 & 27.57 & 43.39 & 25.99 & 43.39 \\
\hline Mean & 23.74 & 14.92 & 17.20 & 37.29 & 20.75 & 32.57 \\
\hline SD & 3.64 & 3.71 & 5.35 & 4.31 & 4.13 & 8.67 \\
\hline \multicolumn{7}{|l|}{$\mathrm{M}_{\mathrm{g}} / \mathrm{L}_{\mathrm{t}}(\mathrm{g} / \mathrm{m})$} \\
\hline Minimum & 66.42 & 28.47 & 28.47 & 87.25 & 43.15 & 43.15 \\
\hline Maximum & 104.77 & 82.49 & 104.77 & 168.92 & 95.22 & 168.92 \\
\hline Mean & 87.74 & 54.30 & 63.66 & 142.95 & 77.08 & 124.13 \\
\hline SD & 15.62 & 13.58 & 20.65 & 17.07 & 15.55 & 34.37 \\
\hline
\end{tabular}

$(6.351<|\mathrm{t}|<10.298, p=0.000$ for all parameters $)$ and farm mink $(3.490<|\mathrm{t}|<13.706,0.000<p<0.001)$. Comparison between wild males and farmed females of similar body size showed that the femoral condyle $\left(\mathrm{W}_{\mathrm{c}}\right.$ and $\left.\mathrm{H}_{\mathrm{c}}\right)$ and head $\left(\mathrm{D}_{\mathrm{h}}\right.$ and $\mathrm{L}_{\mathrm{h}}$ ) were significantly larger in wild males $(|\mathrm{t}|=3.744$, $p=0.002$ for $\mathrm{W}_{\mathrm{c}} ;|\mathrm{t}|=3.466, p=0.003$ for $\mathrm{H}_{\mathrm{c}} ;|\mathrm{t}|=3.529$, $p=0.003$ for $\mathrm{D}_{\mathrm{h}} ;|\mathrm{t}|=3.797, p=0.001$ for $\mathrm{L}_{\mathrm{h}}$ ). However, diameters of the femoral diaphysis were similar for males and females $\left(|\mathrm{t}|=0.725, p=0.479\right.$ for $\mathrm{D}_{\mathrm{mj}}$ and $|\mathrm{t}|=0.210$, $p=0.836$ for $\left.\mathrm{D}_{\mathrm{nm}}\right)$. When the data for two sexes were pooled within each group, means differed between wild and farm mink for all parameters $(7.901<|\mathrm{t}|<10.915, p=0.000$ for all parameters).

Comparisons of the distinctiveness of the GE below the femoral condyle showed that most wild mink had indistinct to moderately distinct GE. In contrast, most farmed mink had a moderately to extremely distinct GE (Fig. 3). In contrast to females, males tended to have an indistinct GE in the wild group and an extremely distinct GE in the farm group.

\section{Structural properties of hindlimb levers}

The moment arm of the femur lever $\left(\mathrm{L}_{\mathrm{f}}\right)$ was significantly sexually dimorphic. $\mathrm{L}_{\mathrm{f}}$ averaged $51.5 \mathrm{~mm}$ for wild males, $44.1 \mathrm{~mm}$ for wild females, 58.1 for farmed males, and $50.0 \mathrm{~mm}$ for farmed females (Table 1). Means differed by sex in both wild $(|\mathrm{t}|=9.222, p=0.000)$ and farm mink $(|t|=10.516, p=0.000)$. When the data for two sexes were pooled, mean $\mathrm{L}_{\mathrm{f}}$ was $46.3 \mathrm{~mm}$ for wild mink, significantly smaller than $55.8 \mathrm{~mm}$ for farm mink $(|\mathrm{t}|=9.374, p=0.000)$.

A similar trend was documented for the tibia lever. Mean $\mathrm{L}_{\mathrm{t}}$ was $51.7 \mathrm{~mm}$ for wild males, $44.1 \mathrm{~mm}$ for wild

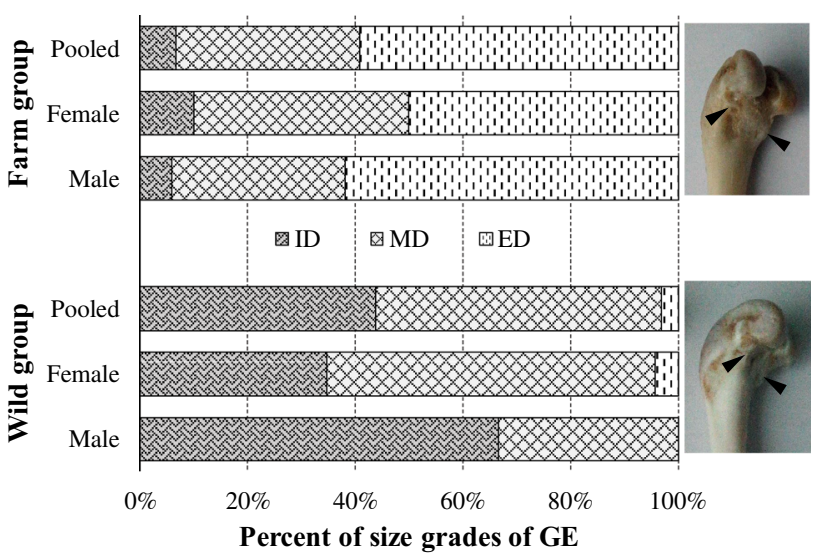

Fig. 3 Percent of size grades of the enthesis of gastrocnemius (GE) on the femur of wild and farmed American mink. GE is the enthesis of gastrocnemius; ID is indistinct; MD is moderately distinct; ED is extremely distinct

females, $58.2 \mathrm{~mm}$ for farmed males, and $49.6 \mathrm{~mm}$ for farmed females, lengths for males being significantly greater than for females among wild $(|\mathrm{t}|=8.406, p=0.000)$ and farm mink $(|\mathrm{t}|=11.076, p=0.000)$. When data for the two sexes were pooled within groups, mean $\mathrm{L}_{\mathrm{t}}$ was $46.3 \mathrm{~mm}$ for wild mink and $55.8 \mathrm{~mm}$ for farm mink, significantly greater for farm mink $(|\mathrm{t}|=8.739, p=0.000)$.

$\mathrm{L}_{\mathrm{f}}$ was proportional to $\mathrm{L}_{\mathrm{t}}$ for all samples (Fig. 4). The mean ratios of $\mathrm{L}_{\mathrm{f}} / \mathrm{L}_{\mathrm{t}}$ were similar for wild males $(0.99)$ and wild females (1.00) $(|\mathrm{t}|=1.159, p=0.257) . \mathrm{L}_{\mathrm{f}} / \mathrm{L}_{\mathrm{t}}$ was 1.00 for farm males and females $(|t|=0.652, p=0.519)$. The difference in means of $\mathrm{L}_{\mathrm{f}} / \mathrm{L}_{\mathrm{t}}$ between wild and farm mink approached significance $(|t|=1.993, p=0.051)$, being 


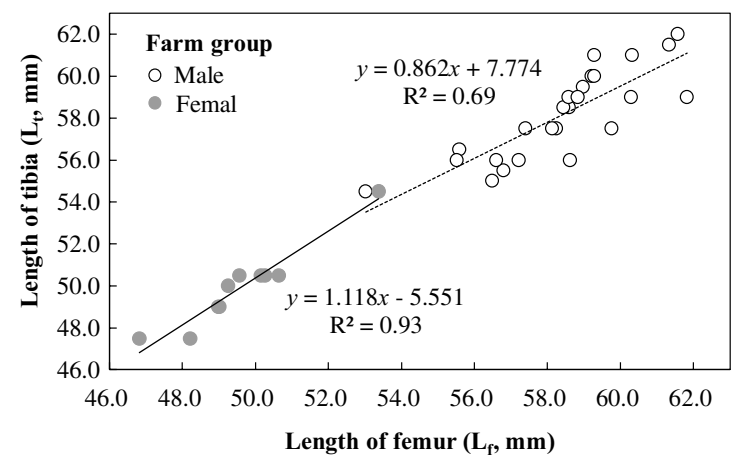

Fig. 4 Regression of length of tibia $\left(L_{t}\right)$ on length of femur $\left(L_{f}\right)$ in wild and farmed American mink. Neither wild nor farm mink differed in their ratios of $\mathrm{L}_{\mathrm{f}} / \mathrm{L}_{\mathrm{t}}$. The inter-sexual differences between regres-

slightly smaller in the wild (Table 1). For wild mink, the slopes of regression curves of $\mathrm{L}_{t}$ on $\mathrm{L}_{\mathrm{f}}$ were slightly greater in males than in females, with a difference of 0.176. This difference reversed for farmed mink that the slope in females was 0.256 greater than males.

\section{Performance property of the femur lever}

The ratio of adductor mass to femur length was used as the parameter to quantify the performance of the femur lever. As shown in Table 1 and Fig. 5, $\mathrm{M}_{\mathrm{a}}$ averaged $1.23 \mathrm{~g}$ for wild males, $0.66 \mathrm{~g}$ for wild females, and $0.91 \mathrm{~g}$ when pooled for wild mink; $2.17 \mathrm{~g}$ for farm males, $1.03 \mathrm{~g}$ for farm females, and $1.85 \mathrm{~g}$ when pooled for farmed mink. $\mathrm{M}_{\mathrm{a}}$ was significantly greater for males than for females in both the wild $(|\mathrm{t}|=6.676, p=0.000)$ and farm groups $(|\mathrm{t}|=11.918$, $p=0.000$ ). Pooled $\mathrm{M}_{\mathrm{a}}$ was significantly smaller for wild than for farm mink $(|t|=8.392, p=0.000)$.

Mean $\mathrm{M}_{\mathrm{a}} / \mathrm{L}_{\mathrm{f}}$ of wild males was significantly greater than for wild females $(|t|=5.439, p=0.000)$. The difference was even greater between farm males and females $(|t|=10.367$, $p=0.000$ ). When data for both sexes were pooled, the difference in $\mathrm{M}_{\mathrm{a}} / \mathrm{L}_{\mathrm{f}}$ was significant between wild and farm mink $(|\mathrm{t}|=8.089, p=0.000)$, but was greater for the farm group than for the wild group.

\section{The axial load on the tibia}

The ratio of gastrocnemius mass to the length of tibia was used to quantify the axial load to the tibia by the gastrocnemius during contraction to lift the heel. As shown in Table 1 and Fig. 5, Mean $\mathrm{M}_{\mathrm{g}}$ was $1.21 \mathrm{~g}$ for wild males, $0.68 \mathrm{~g}$ for wild females, and $0.81 \mathrm{~g}$ when pooled. $\mathrm{M}_{\mathrm{g}}$ was $1.98 \mathrm{~g}$ for farm males, $0.98 \mathrm{~g}$ for farm females, and $1.69 \mathrm{~g}$ when pooled. The between-sex differences were significant in both wild $(|\mathrm{t}|=2.179, p=0.038)$ and farm mink $(|\mathrm{t}|=11.219$, $p=0.000) . \mathrm{M}_{\mathrm{g}}$ was significantly smaller for wild than for

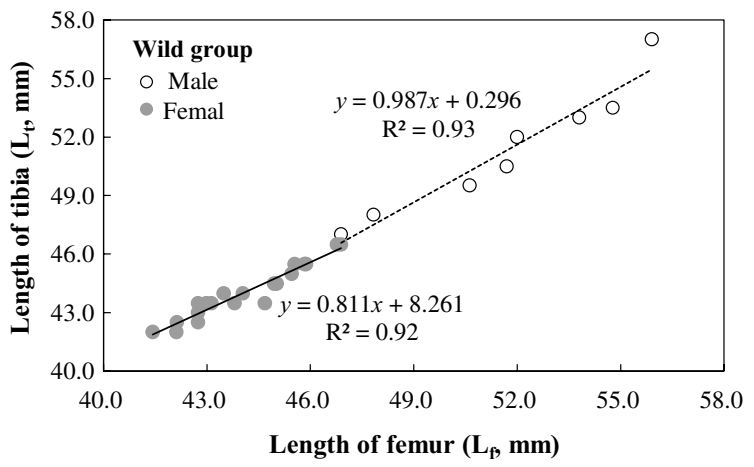

sion slopes of $\mathrm{L}_{t}$ on $\mathrm{L}_{\mathrm{f}}$ were smaller for wild mink $(\mathrm{d}=0.176)$ than for farm mink $(\mathrm{d}=0.256)$

farm mink when data for both sexes were pooled $(|\mathrm{t}|=8.672$, $p=0.000$ ). Mean $\mathrm{M}_{\mathrm{g}} / \mathrm{L}_{\mathrm{t}}$ for males was greater than for females for both wild $(|t|=4.447, p=0.000)$ and farm mink $(|t|=10.559, p=0.000)$, and the farm group ratio was greater than that of the wild group $(|t|=8.192, p=0.000)$.

\section{Discussion}

All farmed and feral mink used in this study were derived from the same strain and therefore expected to have similar genetic backgrounds. We attribute the variation in structure and performance of hindlimb levers studied here to ontogeny in differing environments. We used two extreme conditions to test the influence of environment on ontogeny of hindlimb levers: captive mink were reared in small cages where many behaviors are typically constrained or precluded (Dawkins 1988; Axelsson et al. 2009), while feral mink ranged freely in the wild with no constraints on their behaviors.

The captive-reared mink maintained sexual dimorphism in the structure of their hindlimb levers. This species is characterized by many sexually dimorphic characters (Thom et al. 2004; Korablev et al. 2013; Stevens and Kennedy 2005). These have been largely explained by resource partitioning in which males have a competitive advantage over females in feeding and/or hunting larger prey from subadult through adult age (Thom et al. 2004; Meleroa et al. 2012). We recorded significant sexual dimorphism in the shape of the femoral condyle and its head, the length and diaphysis diameters of the femur, the length of tibia, and the mass of adductor and gastrocnemius: all were greater among males than among females for both wild and farm groups. All these parameters are related to the performance of hindlimb levers in predation and escape. The retention of sexual dimorphism in these parameters among farmed mink suggests that captive breeding for more than 90 generations (since the start of farming in the 1920s) did not significantly reduce the 

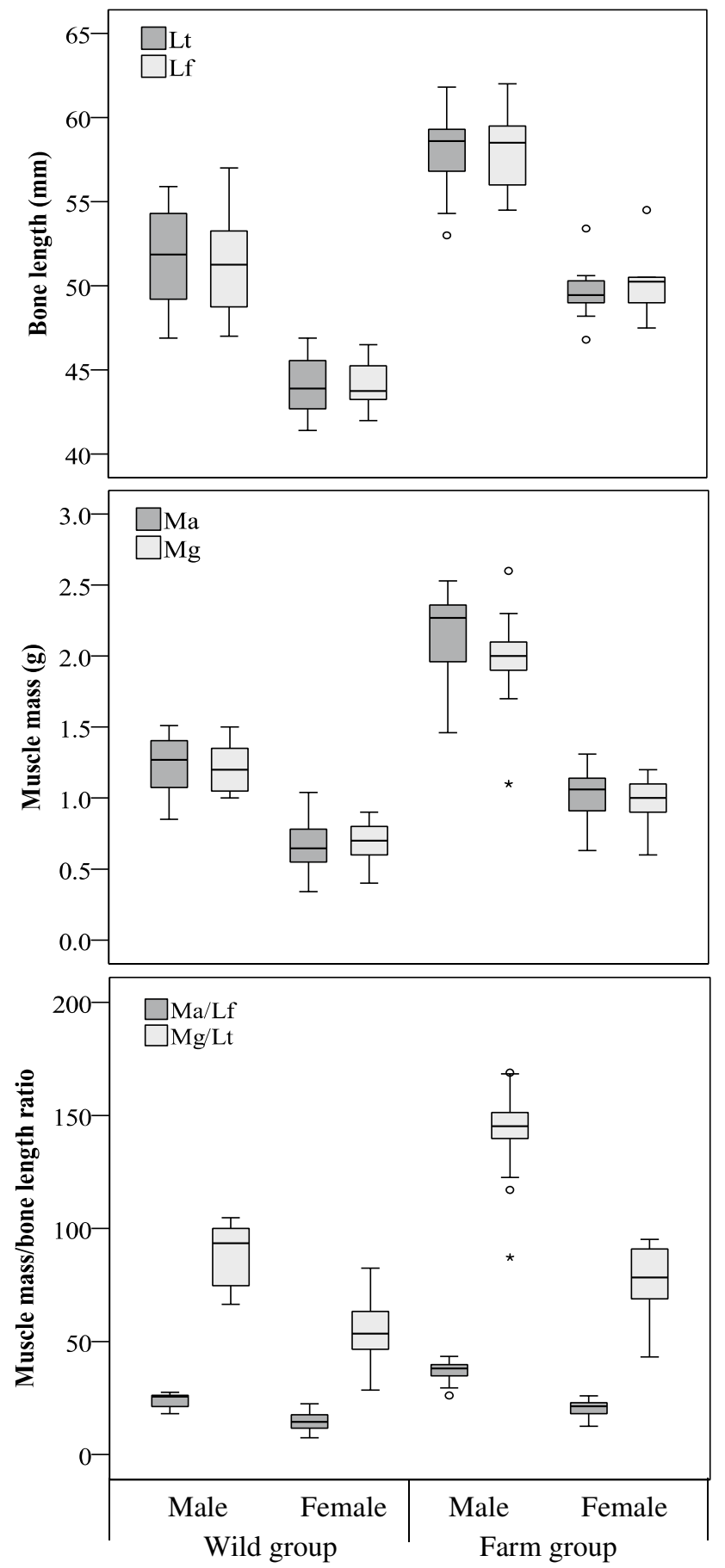

Fig. 5 Data distribution of hindlimb lever indices. Lt: Length of tibia; Lf: Length of femur; Ma: Mass of adductor; Mg: mass of gastrocnemius

skeletal capacity for predation and/or escape needed for survival in the wild. Based on these parameters, the captive-reared mink retained features that would be expected to promote their survival in the wild.

There is a trade-off for the structure of hindlimb levers between foraging in terrestrial and aquatic environments.
Longer femurs and tibias contribute to improved locomotion performance on land (Saiyed Zubeir et al. 2015; Harris and Steudel 2002; Abhishek et al. 2012; James and Wilson 2008) compared to shorter leg bones (Williams et al. 2002; Williams 1983a, b). However, long limbs may add hydrodynamic drag during swimming (Fish 2000). This could be the case for American mink, which lacks specialized appendages for swimming, its feet are relatively small, and its toes are only slightly webbed (Williams 1983a, b). Feral mink would be expected to maintain a trade-off of optimal locomotion performance on land and in water. Our results showed the mean $\mathrm{L}_{\mathrm{f}} / \mathrm{L}_{\mathrm{t}}$ ratio of farm mink was greater than that of feral mink $(p=0.051)$. Meanwhile, the regression slopes of $\mathrm{L}_{\mathrm{t}}$ on $\mathrm{L}_{\mathrm{f}}$ were slightly greater in females than in males (Fig. 4), indicating females tended to have longer tibias than males in relation to the length of the femur. However, the intersexual difference for wild mink (0.176) was considerably less than that $(0.256)$ for farm mink. These inter-group and inter-sexual differences suggest that the wild environment constrains more strictly the hindlimb lever structure to achieve optimal locomotion performance for both terrestrial and aquatic habitats, while the captive environment relaxed the constraint, enabling greater variation to persist. Given that the $\mathrm{L}_{\mathrm{f}} / \mathrm{L}_{\mathrm{t}}$ ratio of feral mink was regarded as the optimal lever structure for survival in the wild, captive mink, especially females might be expected to suffer reduced capacity for locomotion if released to the wild.

We found that captive breeding improved the efficiency of hindlimb levers when muscular force was taken into account. The adductor provides force to move the femur rearward around the pivot of the hip joint. The efficiency of force applied to the lever is a crucial factor affecting lever performance. The maximal force that a muscle generates is positively linearly related to its cross-sectional area (Fukunaga et al. 2001). More recent study suggests that muscle mass is also a useful predictor of maximum force in linear function (Brechue and Abe 2002). We used the ratio of adductor mass to femur length $\left(\mathrm{M}_{\mathrm{a}} / \mathrm{L}_{\mathrm{f}}\right)$ to quantify the efficiency as the force per unit length of moment arm. We found the ratio was significantly greater among farm mink than among wild mink (Table 1, Fig. 5), suggesting farm mink had more powerful femur lever than feral mink. This could be explained as a result of greater loading on the hindlimbs of the farm group. Farm mink spend about $20-30 \%$ of their active time in standing or sitting on hindlimbs with their body held up (Hua et al. 2011), a posture unlikely to be so frequently assumed in the wild. This posture places the entire body weight on the hindlimbs. The hindlimb muscles of farm mink are subject to greater resistance and this might result in greater hypertrophy of hindlimb muscles in farm than in wild mink (Figueiredo et al. 2018; Schoenfeld et al. 2019). These results suggest the efficiency of hindlimbs has been increased among captive-reared mink. 
The long bones of limbs often bear five types of mechanical loads namely axial compression, tension, shear, torsion, and bending. Axial compression can positively impact on cortical and cancellous architecture and lead to significant increases in structural- and tissuelevel mechanical behavior in the diaphysis (Berman et al. 2015). The gastrocnemius provides force to lift the heel with the pivot of the knee joint. The force also acts as the axial compression on the tibia. We used the ratio of gastrocnemius mass to tibia length $\left(\mathrm{M}_{\mathrm{g}} / \mathrm{L}_{\mathrm{t}}\right)$ to quantify the compression load per unit length of tibia. Results showed the ratio was significantly greater among farm mink than among wild mink (Table 1, Fig. 5). We also attribute it to the greater hypertrophy of the gastrocnemius in farm than in wild mink. The gastrocnemius load is transferred to entheses below the femoral condyle and influences the robusticity of entheses as we recorded (Fig. 3) (Hawkey and Merbs 1995; Mariotti et al. 2007; Foster et al. 2014). In the light of findings of Berman et al. (2015), the tibia's architecture and mechanical behavior might have been improved among captive-reared mink.

All these skeletomuscular alterations of hindlimb levers resulted ontogenetically according to the following sequence: abnormally high duration in sitting posture led to hypertrophy of muscles, which, in turn, resulted in skeletal alteration, viz. the fundamental structure of the hindlimb levers and robusticity of entheses. Skeletal muscles have great plasticity and a reduction of resistance loads could therefore result in muscle atrophy (Bruton 2002), while bone length and robusticity of entheses were not altered by load reduction. We attribute the recorded improvement in hindlimb efficiency among farm mink to muscle hypertrophy. When muscle mass declined to the level of wild mink, efficiency would be dramatically reduced and this would lower survival in the wild.

Several points are relevant to the reintroduction of mustelids similar to American mink in body structure and behavior. First, captive breeding in confined and simple environments did not alter sexual dimorphism, but slightly altered the fundamental structure of the hindlimb levers. The lever structure, i.e., the force arm lengths and robusticity of entheses, was essentially unalterable after it was ontogenetically established. The efficiency of the lever is influenced by the capacity of muscular force applied to it, which is fairly plastic in response to environmental stimuli. If muscle development cannot adequately compensate the reduction of structure-oriented efficiency, post-release survival would be expected to be low. Therefore, reintroduction programs of juvenile mustelids would be expected to yield higher post-release survival than would releases of adults. This is because of the degree of plasticity in pre-adult development of the limb skeleton during adaptation to wild environments. Also, the muscular systems of juvenile mink show plasticity adequate to accommodate skeletal development during their remaining pre-adult life span.

Acknowledgements We deeply thank Mr. Yue Ma, Zhen Wang of State Forestry and Grassland Administration Detecting Center of Wildlife for their assistance in data collection and sample treatment. We also specially thank Dr. Philip Stott of the School of Veterinary Medicine, City University of Hong Kong, Hong Kong SAR, China for his valuable recommendations on morphological analysis and discussions during the manuscript preparation.

Open Access This article is distributed under the terms of the Creative Commons Attribution 4.0 International License (http://creativeco mmons.org/licenses/by/4.0/), which permits unrestricted use, distribution, and reproduction in any medium, provided you give appropriate credit to the original author(s) and the source, provide a link to the Creative Commons license, and indicate if changes were made.

\section{References}

Abhishek S, Deepak M, Davinder KG, Waseem M (2012) Correlation of femoral shaft length and tibia length with the performance of athletes in speed, agility and strength. Med Sport 8(3):1922-1926

Axelsson HMK, Aldén E, Lidfors L (2009) Behaviour in female mink housed in enriched standard cages during winter. Appl Anim Behav Sci 121:222-229

Berman AG, Clauser CA, Wunderlin C, Hammond MA, Wallace JM (2015) Structural and mechanical improvements to bone are strain dependent with axial compression of the tibia in female C57BL/6 mice. PLoS ONE 10(6):e0130504

Biggins DE, Vargas A, Godbey JL, Anderson SH (1999) Influence of prerelease experience on reintroduced black-footed ferrets (Mustela nigripes). Biol Conserv 89:121-129

Blumstein DT, Mari M, Daniel JC, Ardron JG, Griffin AS, Evans CS (2002) Olfactory predator recognition: wallabies may have to learn to be wary. Anim Conserv 5:87-93

Box HO (1991) Training for life after release: simian primates as examples. Symp Zool Soc Lond 62:111-123

Brechue WF, Abe T (2002) The role of FFM accumulation and skeletal muscle architecture in powerlifting performance. Eur J Appl Physiol 86:327-336

Bremner-Harrison S, Prodohl PA, Elwood RW (2004) Behavioural trait assessment as a release criterion: boldness predicts early death in a reintroduction programme of captive-bred swift fox (Vulpes velox). Anim Conserv 7:313-320

Bright PW (2000) Lessons from lean beasts: conservation biology of the mustelids. Mammal Rev 30(3-4):217-226

Bruton A (2002) Muscle plasticity: response to training and detraining. Physiotherapy 88:398-408

Burger EH, Klein-Nulen J (1999) Responses of bone cells to biomechanical forces in vitro. Adv Dent Res 13:93-98

Carrier DR (1996) Ontogenetic limits on locomotor performance. Physiol Zool 69:467-488

Dawkins MS (1988) Behavioural deprivation: a central problem in animal welfare. Appl Anim Behav Sci 20:209-225

Figueiredo VC, de Salles BF, Trajano GS (2018) Volume for muscle hypertrophy and health outcomes: the most effective variable in resistance training. Sport Med 48:499-505

Fish FE (2000) Biomechanics and energetics in aquatic and semiaquatic mammals: platypus to whale. Physiol Biochem Zool 73:683-698 
Flück M (2006) Functional, structural and molecular plasticity of mammalian skeletal muscle in response to exercise stimuli. J Exp Biol 209:2239-2248

Foster A, Buckley H, Tayles N (2014) Using enthesis robusticity to infer activity in the past: a review. J Archaeol Method Theory 21:511-533

Fukunaga T, Miyatani M, Tachi M, Kouzaki M, Kawakami Y, Kanehisa $\mathrm{H}$ (2001) Muscle volume is a major determinant of joint torque in humans. Acta Phys Scand 172:249-255

Griffin AS, Blumstein DT, Evans CS (2000) Training captive bred or translocated animals to avoid predators. Conserv Biol 14:1317-1326

Griffin AS, Evans CS, Blumstein DT (2001) Learning specificity in acquired predator recognition. Anim Behav 62:577-589

Guo YR, Wang LL, Jin Y (2006) Opportunity, challenges and countermeasures of wildlife farming in Great Xingan Mountains Region. Chin J Wildl 27(5):29-31

Hansen SW (1996) Selection for behavioural traits in farm mink. Appl Anim Behav Sci 49:137-148

Hansen BK, Su G, Berg P (2010) Genetic variation in litter size and kit survival of mink (Neovison vison). J Anim Breed Genet 127:442-451

Harris MA, Steudel K (2002) The relationship between maximum jumping performance and hind limb morphology/physiology in domestic cats (Felis silvestris catus). J Exp Biol 205:3877-3889

Hawkey DE, Merbs CF (1995) Activity-induced musculoskeletal stress markers (MSM) and subsistence strategy changes among ancient Hudson Bay Eskimos. Int J Osteoarchaeol 5:324-338

Higham TE (2007) The integration of locomotion and prey capture in vertebrates: morphology, behavior, and performance. Integr Comp Biol 47:82-95

Hua Y, Liu R, Liu X (2011) Preliminary study on the behavioral profile of the American mink in captivity. Heilongjiang Anim Sci Vet Med 11:137-139

James RS, Wilson RS (2008) Explosive jumping: extreme morphological and physiological specializations of Australian rocket frogs (Litoria nasuta). Physiol Biochem Zool 81(2):176-185

Järvinen TLN, Pajamäki I, Sievänen H, Vuohelainen T, Tuukkanen J, Järvinen M, Kannus P (2003) Femoral neck response to exercise and subsequent deconditioning in young and adult rats. J Bone Miner Res 18:1292-1299

Jule KR, Leaver LA, Lea SEG (2008) The effects of captive experience on reintroduction survival in carnivores: a review and analysis. Biol Conserv 14(2):355-363

Kleiman DG (1989) Reintroduction of captive mammals for conservation: guidelines for reintroducing endangered species into the wild. Bioscience 39:152-161

Korablev MP, Korablev NP, Korablev PN (2013) Population aspects of sexual dimorphism in Mustelidae from the example of four species (Mustela lutreola, Neovison vison, Mustela putorius, and Martes martes). Biol Bull 40:61-69

Larivière S (1999) Mustela vison. Mammal Species 608:1-9

Lodé T, Cormier JP, Le Jacques D (2001) Decline in endangered species as an indication of anthropic pressures: the case of European mink Mustela lutreola western population. Environ Manag 28:727-735

Maran T, Põdra M, Põlma M, Macdonald DW (2009) The survival of captive-born animals in restoration programmes - case study of the endangered European mink Mustela lutreola. Biol Conserv 142:1685-1692

Marini M, Veicsteinas A (2010) The exercised skeletal muscle: a review. Eur J Transl Myol Myol Rev 20(3):105-120

Mariotti V, Facchini F, Belcastro MG (2007) The study of entheses: proposal of a standardised scoring method for twenty-three entheses of the postcranial skeleton. Coll Antropol 31:291-313
Meleroa Y, Santulli G, Gómez A, Gosàlbez J, Rodriguez-Refojos C, Palazón S (2012) Morphological variation of introduced species: the case of American mink (Neovison vison) in Spain. Mammal Biol 77:345-350

Priddel D, Wheeler R (1996) Effect of Age at release on the susceptibility of captive-reared malleefowl Leipoa ocellata to predation by the introduced fox Vulpes vulpes. EMU 96:32-41

Robert A, Sarrazin F, Couvet D, Stephane Legendre S (2004) Releasing adults versus young in reintroductions: interactions between demography and genetics. Conserv Biol 18:1078-1087

Rönningen K, Olausson A, Rosberg S-O, Johansson I (1980) The use of selection index theory to select breeding females in mink: a preliminary study. Z Tierzüch Züchtungsbiol 97(1-4):166-175

Saiyed Zubeir M, Pais V, Afshan S, Shemjaz A, Pais S (2015) Relationship of limb girth, segmental limb length, hamstring flexibility with vertical jump in male sports players. Int J Curr Res Rev 7:72-75

Sarrazin F, Legendre S (2000) Demographic approach to releasing adults versus young in reintroductions. Conserv Biol 14:488-500

Schoenfeld BJ, Contreras B, Krieger J, Grgic J, Delcastillo K, Belliard R, Alto A (2019) Resistance training volume enhances muscle hypertrophy but not strength in trained men. Med Sci Sports Exerc 51:94-103

Shepherdson D (1994) The role of environmental enrichment in the captive breeding and reintroduction of endangered species. In: Olney PJS, Mace GM (eds) Creative conservation: interactive management of wild and captive animals. Springer, Cham, pp $167-177$

Shier DM, Owings DH (2006) Effects of predator training on behavior and post-release survival of captive prairie dogs (Cynomys ludovicianus). Biol Conserv 132:126-135

Shier DM, Owings DH (2007) Effects of social learning on predator training and postrelease survival in juvenile black-tailed prairie dogs, Cynomys ludovicianus. Anim Behav 73:567-577

Stevens RT, Kennedy ML (2005) Spatial patterns of sexual dimorphism in minks (Mustela vison). Am Midl Nat 154:207-216

Stoinski TS, Beck BB (2004) Changes in locomotor and foraging skills in captive-born, reintroduced golden lion tamarins (Leontopithecus rosalia rosalia). Am J Primatol 62:1-13

Thom MD, Harrington LA, Macdonald DW (2004) Why are American mink sexually dimorphic? A role for niche separation. Oikos 105:525-535

Vargas A, Anderson SH (1999) Effects of experience and cage enrichment on predatory skills of black-footed ferrets (Mustela nigripes). J Mammal 80(1):263-269

Williams TM (1983a) Locomotion in the north American mink, a semiaquatic mammal. II. The effect of an elongate body on running energetics and gait patterns. J Exp Biol 105:283-295

Williams TM (1983b) Locomotion in the north American mink, a semi-aquatic mammal. I. Swimming energetics and body drag. J Exp Biol 103:155-168

Williams TM, Ben-David M, Noren S, Rutishauser M, McDonald K, Heyward W (2002) Running energetics of the North American river otter: do short legs necessarily reduce efficiency on land? Comp Biochem Physiol A 133:203-212

Publisher's Note Springer Nature remains neutral with regard to jurisdictional claims in published maps and institutional affiliations. 